\title{
Correlations between serum adipocytokine concentrations, disease stage, radiological status and total body fat content in the patients with primary knee osteoarthritis
}

\author{
Magdalena Richter ${ }^{1}$ • Tomasz Trzeciak ${ }^{1}$ - Jakub Dalibor Rybka ${ }^{2,3}$. \\ Wiktoria Suchorska ${ }^{4,5}$. Ewelina Augustyniak ${ }^{4,6}$ • Michal Lach ${ }^{4,6}$. \\ Malgorzata Kaczmarek $^{1}$ • Jacek Kaczmarczyk ${ }^{1}$
}

Received: 28 September 2016 / Accepted: 4 December 2016/Published online: 24 December 2016

(C) The Author(s) 2016. This article is published with open access at Springerlink.com

\begin{abstract}
Purpose The study was designed to investigate whether serum concentrations of leptin, resistin and adiponectin in obese and normal-weight patients with primary knee osteoarthritis (OA) correlate with clinical and radiological stages of the disease and percentage of total body fat.

Methods Seventy-three patients with knee OA, divided into obese and normal-weight groups, were clinically evaluated according to the Knee Society Score (KSS), and radiologically assessed using Kellgren and Lawrence scale. The percentage of total body fat and some anthropometric data were also given. Serum leptin, resistin and adiponectin concentrations were measured by Elisa and were correlated with the clinical, radiological and anthropometric parameters.

Results Leptin concentrations were significantly higher $(p=0.001)$ in the obese patients and positively correlated
\end{abstract}

Magdalena Richter and Tomasz Trzeciak contributed equally to this work.

Tomasz Trzeciak

doktortrzeciak@gmail.com

1 Department of Orthopaedics and Traumatology, Poznan University of Medical Sciences, 28 Czerwca 1956 St., 135/147, 61-545 Poznan, Poland

2 Faculty of Chemistry, Adam Mickiewicz University, Poznan, Poland

3 Wielkopolska Centre of Advanced Technologies, Adam Mickiewicz University, Poznan, Poland

4 Greater Poland Cancer Centre, Radiobiology Laboratory, Poznan, Poland

5 Department of Electroradiology, Poznan University of Medical Sciences, Poznan, Poland

6 The Postgraduate School of Molecular Medicine, Medical University of Warsaw, Warsaw, Poland
$(\mathrm{R}=0.63)$ with radiologically assessed OA grade, but only in the normal-weight group. Resistin and adiponectin concentrations were identical in obese and normal-weight patients and negatively correlated $(\mathrm{R}=-0.41)$ with the clinical status of obese patients. In both groups, percentage of total body fat positively correlated $(\mathrm{R}=0.29$ and $\mathrm{R}=0.53$ for obese and normal-weight respectively) with radiologically assessed OA grade. However, no correlations were found with clinical status of the patients.

Conclusions It was found that in the obese patients with knee OA, increased percentage of total body fat and elevated serum leptin concentration might favour the advancement of clinical but not radiologically assessed changes in the joint structures, while in normal-weight patients it correlates only with radiologically assessed changes but does not affect to an appreciable extent the clinical status of the patients.

Keywords Osteoarthritis · Obesity $\cdot$ Leptin $\cdot$ Resistin · Adiponectin

\section{Introduction}

Osteoarthritis $(\mathrm{OA})$ is a multivariate degenerative disease of synovial joints resulting from both mechanical and biological factors, among which sex, age, genetic factors, trauma and obesity play the most important role [1]. The influence of obesity on the development of OA was recognised either in respect to the mechanical load leading to increased feasibility of damage of the joint structures [2], or as a result of activation of mechanoreceptors on cartilage surface, which in turn can lead to the synthesis of the inflammatory mediators [3]. In the mid-1990s, due to the discovery of leptin, the first adipocyte-derived cytokine [4], it has been shown that the white adipose tissue (WAT) produces 
several substances, called adipocytokines, which can act similarly to the classic endocrine hormones. Adipocytokines were recognised as modulators of the energy homeostasis, as well as an immunological, haemostatic and inflammatory processes [5]. Those substances also play an important role in the degradation processes of cartilage, bone and synovium [6]. Since their effect on the degenerative changes in non-loaded joints were demonstrated [7], they might provide a link between obesity and OA. Among adipocytokines, leptin, resistin and adiponectin were the most extensively studied [8].

Human leptin is encoded by the obese gene $(O B)$ and its activity is mediated by the $\mathrm{OB}$ receptor encoded by the diabetes gene $(D B)$. Leptin is produced mainly by adipocytes of the subcutaneous white adipose tissue (WAT), as well as by the glandular cells of the stomach, liver and mammary gland [9]. It acts on the central nervous system regulating energy balance by inhibiting hunger, increasing energy expenditure and thermogenesis. It also demonstrates similarity to the action of insulin in the ability to lower blood glucose level [10]. Leptin pro-inflammatory effect depends on stimulation of the T-lymphocytes. This in turn increases the levels of TNF- $\alpha$ and interleukins, which precedes the activation the of the NK cells, macrophages and neutrophils [11].

Resistin, encoded by the RSTN gene, is produced mainly in the WAT, as well as in the bone marrow, spleen, lungs, placenta and pancreas. Resistin increases the secretion of proinflammatory cytokines (TNF- $\alpha$, IL-6 and IL-12) by macrophages [12]. Intraarticular injection of resisitin in mice, resulted in joint inflammation, resembling human arthritis [13]. Apart from the inflammatory processes, it also plays a role in adipogenesis and shows a positive correlation with insulin resistance and obesity [14].

Adiponectin, encoded by the $A D P O Q$ gene, is produced by the WAT and visceral adipose tissue and is implicated in carbohydrate and lipid metabolism, and thermoregulation. It also increases cell sensitivity to insulin in muscle and liver. The concentration of adiponectin in plasma is higher in females and correlates with degenerative join diseases and rheumatoid arthritis $[15,16]$. Less information is available on the effect of adiponectin in the inflammatory processes, although its role in interleukins (IL-1 $\beta$, IL-6), metaloproteins (MMP-13, MMP-1 and MMP-3) and nitric oxide (NO) secretion was reported [17].

To date, very few investigations have been made on the effects of these adipocytokines on the radiological features and clinical status of the patients with knee OA.

We hypothesised that there might be a correlation between serum concentration of leptin, resistin and adiponectin, total body fat, and the radiological and clinical advancement of changes in the knee joints in patients with primary OA.

\section{Materials and methods}

From a total of 186 patients with knee OA treated in the Department of Orthopaedics and Traumatology, a group of 73 patients with primary OA was carefully selected, according to the criteria developed by the American College of Rheumatology [18]. Individuals with any evidence of secondary OA, inflammatory arthritis and those with neurological conditions were excluded from the study, along with subjects with acute or chronic renal disease, metabolic syndrome, heart diseases and epilepsy. Fiftysix patients with body mass index (BMI) $\geq 30$ were included in the obese group (group I) while 17 patients with normal BMI were included in the normal-weight group (group II). The knee radiographs were evaluated by two independent orthopaedists using Kellgren-Lawrence criteria [19]. The clinical advancement of OA was assessed with the Knee Society Score [20]. The anthropometric characteristics of the patients are summarised in Table 1. The research Ethics Board of Poznan University of Medical Sciences approved the study (decision no. 387/13).

Anthropometric measurements were taken at the time of diagnosis. The patients were weighted with calibrated scale to the

Table 1 Characteristics of patients with OA

\begin{tabular}{|c|c|c|c|c|c|c|}
\hline \multirow[t]{2}{*}{ Variables } & \multicolumn{3}{|l|}{ Obese } & \multicolumn{3}{|l|}{ Normal weight } \\
\hline & Total $(n=56)$ & Males $(n=11)$ & Females $(n=45)$ & Total $(n=17)$ & Males $(n=6)$ & Females $(n=11)$ \\
\hline Age & $66 \pm 6$ & $68 \pm 6$ & $66 \pm 6$ & $65 \pm 6$ & $63 \pm 8$ & $66 \pm 5$ \\
\hline Weight (kg) & $87.0 \pm 10.7$ & $97.1 \pm 8.7$ & $84.5 \pm 9.7$ & $66.3 \pm 7.2$ & $73.5 \pm 6.1$ & $62.4 \pm 4.2$ \\
\hline Height (cm) & $161 \pm 8$ & $174 \pm 8$ & $157 \pm 5$ & $164 \pm 8$ & $173 \pm 6$ & $159 \pm 5$ \\
\hline BMI $\left(\mathrm{kg} / \mathrm{m}^{2}\right)$ & $33.48 \pm 3.17$ & $32.1 \pm 2.2$ & $33.8 \pm 3.3$ & $24.6 \pm 0.5$ & $25.5 \pm 0.4$ & $24.6 \pm 0.5$ \\
\hline Waist circumference $(\mathrm{cm})$ & $99 \pm 8$ & $105 \pm 5$ & $98 \pm 8$ & $87 \pm 5$ & $90 \pm 7$ & $85 \pm 3$ \\
\hline Hip circumference (cm) & $112 \pm 8$ & $109 \pm 5$ & $113 \pm 8$ & $100 \pm 6$ & $97 \pm 7$ & $102 \pm 7$ \\
\hline WHR & $0.88 \pm 0.07$ & $0.97 \pm 0.04$ & $0.86 \pm 0.06$ & $0.86 \pm 0.07$ & $0.92 \pm 0.07$ & $0.83 \pm 0.05$ \\
\hline
\end{tabular}

Values are expressed as means $\pm \mathrm{SD}$

$B M I$ body mass index, WHR waist-hip ratio 
nearest $0.1 \mathrm{~kg}$ in minimum clothing and standing height were measured with stadiometer. Waist and hip circumference was measured by standard procedure and skinfolds' thickness (biceps, triceps, subscapular and iliac crest) according to ISAK (International Society for the Advancement of Kinanthropometry) with a Harpenden caliper (Baty International, Burgess Hill, UK), to the nearest $0.2 \mathrm{~cm}$. The BMI and waist-hip ratio (WHR) were then calculated. Total body fat was calculated from BMI according to formulae developed by Deurenberg et al. [21]. The equation of Durnin and Womersley [22] was used to predict body density (BD) using the skinfold thickness, then body fat was calculated using the equation of Siri [23]. Body fat content was assessed by bioimpedance analysis (BIA) using a Bodystat 1500 analyser (Bodystat, Douglas, Isle of Man) after ten minutes of rest. The analysis was performed by the same operator for all subjects by placing two electrodes on the right hand and right foot, with the subject in a supine position.

From all patients, fasting blood samples were obtained, serum was separated and aliquoted into tubes (CryoPure; Sarstedt, Nümbrecht, Germany), which were stored at $-20{ }^{\circ} \mathrm{C}$ until analysis. Serum leptin, resistin and adiponectin concentrations were determined in duplicate by an enzyme-linked immunosorbent assay (R\&D Systems; Minneapolis, MN, USA). The absorbance was measured at $450 \mathrm{~nm}$ in an automated ELISA plate reader (Infinite F50; Tecan, Männedorf, Switzerland) and the concentration of adipocytokines were calculated from standard curves. The results were statistically evaluated, and the differences were subjected to linear regression analysis (STATISTICA 10.0; StatSoft, Kraków, Poland).

\section{Results}

The advancement of OA changes in knee joints, determined by radiography, using the K-L grading system, showed no patients graded 0 in both groups. In the obese subjects (group I), there were no patients graded 1 , nine patients graded 2, 16 patients graded 3 and 31 patients graded 4 . In the normalweight subjects (group II), there was one patient graded 1, two patients graded 2 , six patients graded 3 and eight patients graded 4. No appreciable differences in the advancement of changes in knee joints, estimated by the K-L, were found between the two groups.

The evaluation of clinical advancement of OA, by the Knee Society Score (KSS), showed a mean of 64 points (range, 20 90 ) in group I and 62 points (range, 5-100) in group II. The mean functional KSS score was 55 points (range, 5-100) in group I and 64 points (range, 10-90) in group II. No statistically significant differences in all KSS parameters between the groups were found.

The percentage of total body fat, estimated by BMI, skinfolds and BIA, was significantly higher in group I than in group II (Table 2) and in both groups it was significantly higher in females than in males.

In both groups, the percentage of total body fat, calculated on the basis of BMI, correlated with the radiographic advancement of OA, assessed by the K-L grading system $(\mathrm{R}=0.29$, $p=0.028$ for group I, and $\mathrm{R}=0.53, p=0.028$ for group II). There was no correlation, however, between the percentage of total body fat, calculated from the skinfolds' thickness and by the BIA.

There was also no correlation between the percentage of total body fat and the KSS score, and the differences between male and female patients calculated separately (not shown) were insignificant.

In patients from group I, mean serum leptin concentration was higher than in patients from group II $(p=0.001)$, in male as well as in female patients, and in both groups, it was higher in female than in male patients $(p=0.008$ and $p=0.005$ for obese and normal-weight respectively). There were no differences in mean resistin and adiponectin levels between the two groups, although in group I, adiponectin levels were significantly lower compared with the normal weight group and differed significantly $(p=0.031)$ between the genders, while serum resistin levels were not significantly different in the obese male and normal-weight female patients (Table 3).

In group I, serum leptin concentration correlated with the BMI $(\mathrm{R}=0.27, p=0.041)$ and with the percentage of total body fat calculated on the basis of BMI $(\mathrm{R}=0.54$, $p=0.0001)$, skinfolds $(\mathrm{R}=0.50, p=0.0001)$ and BIA
Table 2 The percentage of total body fat measured by different methods in the obese and normalweight patients with knee OA

\begin{tabular}{|c|c|c|c|c|c|c|}
\hline \multirow[t]{2}{*}{ Method } & \multicolumn{3}{|l|}{ Obese } & \multicolumn{3}{|c|}{ Normal weight } \\
\hline & $\begin{array}{l}\text { Total } \\
(n=56)\end{array}$ & $\begin{array}{l}\text { Males } \\
(n=11)\end{array}$ & $\begin{array}{l}\text { Females } \\
(n=45)\end{array}$ & $\begin{array}{l}\text { Total } \\
(n=17)\end{array}$ & $\begin{array}{l}\text { Males } \\
(n=6)\end{array}$ & $\begin{array}{l}\text { Females } \\
(n=11)\end{array}$ \\
\hline BMI & $47.9 \pm 6.3^{*}$ & $38.0 \pm 3.3 *$ & $50.4 \pm 3.9^{*}$ & $35.3 \pm 5.9 *$ & $27.8 \pm 1.9^{*}$ & $39.4 \pm 1.6^{*}$ \\
\hline Skinfolds & $39.1 \pm 4.9^{*}$ & $31.3 \pm 3.0^{*}$ & $41.0 \pm 3.1 *$ & $33.5 \pm 7.2 *$ & $25.7 \pm 5.0^{*}$ & $37.8 \pm 3.6^{*}$ \\
\hline BIA & $43.5 \pm 7.3^{*}$ & $31.7 \pm 3.3^{*}$ & $46.4 \pm 4.6^{*}$ & $33.4 \pm 8.8 *$ & $23.4 \pm 2.8 *$ & $39.0 \pm 5.2 *$ \\
\hline
\end{tabular}

Values are expressed as means \pm SD

$* p<0.05$ denotes difference significant

$B M I$ body mass index, BIA bioimpedance analysis 
Table 3 Serum adipocytokine concentration in the obese and normal-weight patients with OA

\begin{tabular}{|c|c|c|c|c|c|c|}
\hline \multirow[t]{2}{*}{ Adipocytokine } & \multicolumn{3}{|l|}{ Obese } & \multicolumn{3}{|l|}{ Normal weight } \\
\hline & Total $(n=56)$ & Males $(n=11)$ & Females $(n=45)$ & Total $(n=17)$ & Males $(n=6)$ & Females $(n=11)$ \\
\hline Leptin (ng/ml) & $47.99 \pm 40.18^{*}$ & $18.71 \pm 9.45^{*}$ & $55.15 \pm 41.60^{*}$ & $16.49 \pm 14.9^{*}$ & $3.86 \pm 3.88 *$ & $23.38 \pm 14.14^{*}$ \\
\hline Resistin (pg/ml) & $8.16 \pm 4.89$ & $7.54 \pm 5.11$ & $8.31 \pm 4.88$ & $8.47 \pm 11.16$ & $11.35 \pm 18.53$ & $6.89 \pm 4.46$ \\
\hline Adiponectin (ng/ml) & $8.08 \pm 4.66$ & $5.54 \pm 2.95^{*}$ & $8.70 \pm 4.81 *$ & $9.93 \pm 4.07$ & $8.03 \pm 3.26$ & $10.97 \pm 4.23$ \\
\hline
\end{tabular}

Concentrations of adipocytokines are expressed as means $\pm \mathrm{SD}$

${ }^{*} p<0.05$ denotes difference significant between obese and normal-weight patients

$(\mathrm{R}=0.56, p=0.0001)$. There was also a correlation $(\mathrm{R}=0.29$, $p=0.0342$ ) between serum resistin concentration and the percentage of total body fat, calculated on the basis of BMI, and there were no correlations between serum adiponectin and both BMI and percentage of body fat.

In the same group there was a negative correlation ( $\mathrm{R}=-0.41, p=0.001)$ between serum resistin concentration and the advancement of the OA estimated by the KSS score. Unexpectedly, in this group there were no correlations between serum leptin, as well as resistin and adiponectin concentrations and the radiologically assessed advancement of changes in knee joints.

In group II, serum leptin concentration positively correlated with the percentage of total body fat, but only when calculated on the basis of BMI $(\mathrm{R}=0.56, p=0.0186)$ and skinfolds $(\mathrm{R}=0.79$, $p=0.0002)$ and not BIA, while serum adiponectin concentration positively correlated $(\mathrm{R}=0.52, p=0.0313$ ) with the percentage of total body fat, but only when calculated from the thickness of skinfolds. In the same group, serum leptin concentration positively correlated $(\mathrm{R}=0.63, p=0.006)$ with the advancement of the OA determined by the K-L grading system.

\section{Discussion}

Numerous studies indicate an important role of the adipose tissue in the pathogenesis of OA [24, 25]. A correlation was reported between obesity and increased stiffness of knee joints, accompanied by pain $[26,27]$, and it was shown that the percentage of total body fat favours exacerbation of the inflammatory processes and acceleration of the disease progress [28].

It was also demonstrated [29] that a decrease in body mass could alleviate the pain, contributing to the improvement of the functional KSS score, and that the reduction of body fat (but not body mass) alleviates OA symptoms [30]. It was postulated that cytokines, secreted from the adipose tissueleptin, resistin and adiponectin - might influence the progress of OA and the gravity of the symptoms [31].

Our findings on higher leptin concentration in the obese than in normal-weight patients of both sexes (higher in females than in males), correlated with the BMI and the percentage of total body fat substantiating and extending earlier report [32]. However, in contrast to others [33], who showed a correlation between serum leptin levels and progress of the disease, we did not find any correlation with the advancement of radiographic changes in knee joints, estimated by the K-L grading system in the obese patients in agreement with Iwamoto et al. [34] who obtained similar results.

Interestingly, in the normal-weight patients, we found a correlation between serum leptin concentration and the intensity of radiographic changes in the knee joints, smaller in the knee joints in the normal-weight (K-L median 3) than in the obese patients (K-L median 4). This indicates that increase in the concentration of leptin plays a more important role in the assessment of radiological changes in patients with less advanced changes in knee joints than at the final stage of the disease.

Our results are consistent with an earlier report [35] showing a lower concentration of synovial fluid leptin in patients with advanced OA in comparison to those at the initial stages of the disease, and with another report [36] on overexpression of genes encoding IGF-1, TIMP-2, type II collagen and MMP13 in the obese patients, which might be responsible for inhibition of the leptin impact on chondrocytes. These results were confirmed in an animal model [37].

Numerous studies indicate that the local concentration of leptin might be more important for the degeneration of joint structures than its concentration in serum, e.g. Simopoulou et al. [38] noted a much higher concentration of leptin in the synovial fluid than in the serum of patients with knee OA. Local leptin mRNA concentration was higher in obese patients than in those with normal weight, while the concentration of leptin mRNA and its receptor in joint cartilage obtained from the "degenerated" site was higher than from the "healthy" site. Moreover, two groups [39, 40] reported that the concentration of leptin in the synovial fluid correlates with the BMI of the patients, and one [41] that it correlates with the intensity of knee pain.

It was shown that resistin concentration correlated with the occurrence of synovitis, but not with the concentration of cartilage degeneration markers [42], and a correlation between serum resistin concentration, erythrocyte sedimentation rate (ESR) and C-reactive protein (CRP) was described in patients 
with OA [43]. In addition, the results of other studies [44, 45] suggested that there is a correlation between resistin concentration and the degree of clinical progress of hand OA. Although the elevated level of serum resistin was also reported in rheumatoid arthritis [46], others [42] did not find any correlation between serum and synovial fluid concentration of resistin and BMI of the patients with knee OA.

In our study, a negative correlation between serum resistin concentration and the advancement of the degenerative changes in knee joints, evaluated by radiography, was found in the obese patients. However, there were no convincing information on the effects of local concentration of resistin on the radiographic changes in knee joints.

Studies made in patients gave conflicting results regarding the relation of serum adiponectin concentration to the knee OA. A positive correlation between the concentration of adiponectin and the advancement of OA, estimated by the Ahlbäck scale was observed [47] and higher concentration of adiponectin in patients with more advanced osteoarthritis of hand joints was reported [45]. However, others [48] found a negative correlation between the concentration of serum adiponectin and the advancement of the degenerative changes in knee joints estimated by the K-L grading system.

In conclusion, we confirmed earlier reports on higher serum leptin concentration in the obese group of patients with OA compared with the normal-weight group. In the obese patients, elevated serum leptin positively correlated with the BMI and total body fat, but there were no correlations between both the clinical status and the advancement of radiologically assessed changes in the knee joints of the obese patients. In these patients, there was a negative correlation between serum resistin concentration and the advancement of the degenerative changes in knee joints, evaluated by radiography. This might imply that resistin slows down the advancement of the degenerative changes in knee joints. This suggestion, however, can be misleading since in the present report we determined serum resistin concentration and local concentration of resistin had not been measured.

In the normal weight patients, we found a correlation between serum leptin concentration and the advancement of radiological changes in knee joints, estimated by the K-L grading system, suggesting that serum concentration of leptin is more important in the evaluation of changes in the knee joints at the earlier stages than at the final stage of the disease.

In the present study, no differences were found in serum adiponectin concentration between obese and normal-weight patients. Numerous reports from the literature on the effect of adipocytokines on the advancement of changes in knee joints in the obese OA patients often gave conflicting results. Therefore, in order to more precisely define the role of adipocytokines in the origin and advancement of pathological processes in osteoarthritic knee joints in the obese patients, accompanying diseases, such as a metabolic syndrome or diabetes type II, frequent in these patients, should be taken into account.

Our results, although interesting from the point of view of basic science, have only a minor meaning for the clinical practice. In order to make our results suitable for clinical practice, further investigations on the effects of local adipocytokine concentration on the advancement of changes in the knee joints are required.

Compliance with ethical standards This article does not contain any studies with human participants or animals performed by any of the authors.

Informed consent was obtained from all individual participants included in the study.

Funding This study was funded by the National Science Centre (grant number 2012/07/E/NZ3/01819) and the grant from the Dean of Medical Faculty II for Young Scientists, Poznan University of Medical Sciences (grant number 502-14-02217342).

Conflict of interest The authors declare that they have no conflict of interest.

Open Access This article is distributed under the terms of the Creative Commons Attribution 4.0 International License (http:// creativecommons.org/licenses/by/4.0/), which permits unrestricted use, distribution, and reproduction in any medium, provided you give appropriate credit to the original author(s) and the source, provide a link to the Creative Commons license, and indicate if changes were made.

\section{References}

1. Nishimura A, Hasegawa M, Kato K, Yamada T, Uchida A, Sudo A (2011) Risk factors for the incidence and progression of radiographic osteoarthritis of the knee among Japanese. Int Orthop 35:839 843. doi:10.1007/s00264-010-1073-x

2. Sowers MR, Karvonen-Gutierrez CA (2010) The evolving role of obesity in knee osteoarthritis. Curr Opin Rheumatol 22:533-537

3. Ramage L, Nuki G, Salter DM (2009) Signalling cascades in mechanotransduction: cell-matrix interactions and mechanical loading. Scand J Med Sci Sports 19:457-469

4. Zhang Y, Proenca R, Maffei M, Barone M, Leopold L, Friedman JM (1994) Positional cloning of the mouse obese gene and its human homologue. Nature 372:425-432

5. Kershaw EE, Flier JS (2004) Adipose tissue as an endocrine organ. J Clin Endocrinol Metab 89:2548-2556

6. Hu PF, Tang JL, Chen WP, Bao JP, Wu LD (2011) Increased apelin serum levels and expression in human chondrocytes in osteoarthritic patients. Int Orthop 35:1421-1426. doi:10.1007/s00264-010-1100-y

7. Yusuf E, Ioan-Facsinay A, Bijsterbosch J, Klein-Wieringa I, Kwekkeboom J, Slagboom PE, Huizinga TW, Kloppenburg M (2011) Association between leptin, adiponectin and resistin and long-term progression of hand osteoarthritis. Ann Rheum Dis 70: 1282-1284

8. Richter M, Trzeciak T, Owecki M, Pucher A, Kaczmarczyk J (2015) The role of adipocytokines in the pathogenesis of knee joint osteoarthritis. Int Orthop 39:1211-1217. doi:10.1007/s00264-015-2707-9 
9. Meier U, Gressner AM (2004) Endocrine regulation of energy metabolism: Review of pathobiochemical and clinical chemical aspects of leptin, ghrelin, adiponectin and resistin. Clin Chem 50: 1511-1525. doi:10.1373/clinchem.2004.032482

10. Ashima RS, Lazar MA (2008) Adipocytokines and the peripheral and neutral control of energy balance. Mol Endocrinol 22:1023-1031

11. Otero M, Lago R, Lago F, Reino JJ, Gualillo O (2005) Signalling pathway involved in nitric oxide synthase type II activation in chondrocytes: synergistic effect of leptin with interleukin-1. Arthritis Res Ther 7:581-591

12. Silswal N, Singh AK, Aruna B, Mukhopadhyay S, Ghosh S, Ehtesham NZ (2005) Human resistin stimulates the proinflammatory cytokines TNF-alpha and IL-12 in macrophages by NF-kappaB-dependent pathway. Biochem Biophys Res Commun 334:1092-1101

13. Bokarewa M, Nagaey I, Dahlberg L, Smith U, Tarkowski A (2005) Resistin, an adipokine with potent proinflammatory properties. J Immunol 174:5789-5795

14. Wulster-Radcliffe MC, Ajuwon KM, Wang J, Christian JA, Spurlock ME (2004) Adiponectin differentially regulates cytokines in porcine macrophages. Biochem Biophys Res Commun 316: 924-929. doi:10.1016/j.bbrc.2004.02.130

15. Yokota T, Oritani K, Takahashi I, Ishikawa J, Matsuyama A, Ouchi N, Kihara S, Funahashi T, Tenner AJ, Tomiyama Y, Matsuzawa Y (2000) Adiponectin, a new member of the family of soluble defense collagens, negatively regulates the growth of myelomonocytic progenitors and the functions of macrophages. Blood 96:1723-1732

16. Kang EH, Lee YL, Kim TK, Chang CB, Chung JH, Shin K, Lee EY, Lee EB, Song YW (2010) Adiponectin is a potential catabolic mediator in osteoarthritis cartilage. Arthritis Res Ther 12:R231

17. Lago R, Gomez R, Otero M, Lago F, Gallego R, Dieguez C, Gomez-Reino JJ, Gualillo O (2008) A new player in cartilage homeostasis: adiponectin induces nitric oxide synthase type II and pro-inflammatory cytokines in chondrocytes. Osteoarthr Cartil 16: 1101-1109

18. Altman R, Asch E, Bloch D, Bole G, Borenstein D, Brandt K, Christy W, Cooke TD, Greenwald R, Hochberg M et al (1986) Development of criteria for the classification and reporting of osteoarthritis. Classification of osteoarthritis of the knee. Diagnostic and Therapeutic Criteria Committee of the American Rheumatism Association. Arthritis Rheum 29:1039-1049

19. Kellgren JH, Lawrence JS (1957) Radiological assessment of osteoarthrosis. Ann Rheum Dis 16:494-502

20. Insall JN, Dorr LD, Scott RD, Scott WN (1989) Rationale of the knee society clinical rating system. Clin Orthop Relat Res 248:13-14

21. Deurenberg P, Weststrate JA, Seidell JC (1991) Body mass index as a measure of body fatness: age- and sex-specific prediction formulas. Br J Nutr 65:105-114

22. Durnin JV, Womersley J (1974) Body fat assessed from total body density and its estimation from skinfold thickness: measurements on 481 men and women aged from 16 to 72 years. Br J Nutr 32:77-97

23. Siri WE (1961) Body composition from fluid spaces and density: analyses of methods. In: Brozek J, Henschel A (eds) Techniques for measuring body composition. National Academy of Sciences, National Research Council, Washington, pp 223-224

24. Brunner AM, Henn CM, Drewniak EI, Lesieur-Brooks A, Machan J, Crisco JJ, Ehrlich MG (2012) High dietary fat and the development of osteoarthritis in a rabbit model. Osteoarthr Cartil 20:584 592. doi:10.1016/j.joca.2012.02.007

25. Garner M, Alshameeri Z, Khanduja V (2013) Osteoarthritis: genes, nature-nurture interaction and the role of leptin. Int Orthop 37: 2499-2505. doi:10.1007/s00264-013-2088-x

26. Brady SR, Mamuaya BB, Cicuttini F, Wluka AE, Wang Y, Hussain SM, Urquhart DM (2015) Body composition is associated with multisite lower body musculoskeletal pain in a community-based study. J Pain 16:700-706. doi:10.1016/j.jpain.2015.04.006

27. Bas S, Finckh A, Puskas GJ, Suva D, Hoffmeyer P, Gabay C, Lübbeke A (2014) Adipokines correlate with pain in lower limb osteoarthritis: different associations in hip and knee. Int Orthop 38: 2577-2583. doi:10.1007/s00264-014-2416-9

28. Handschin C, Spiegelman BM (2008) The role of exercise and PGC1alpha in inflammation and chronic disease. Nature 454: 463-469

29. Richette P, Poitou C, Garnero P, Vicaut E, Bouillot JL, Lacorte JM, Basdevant A, Clément K, Bardin T, Chevalier X (2011) Benefits of massive weight loss on symptoms, systemic inflammation and cartilage turnover in obese patients with knee osteoarthritis. Ann Rheum Dis 70:139-144

30. Toda Y, Toda T, Takemura S, Wada T, Morimoto T, Ogawa R (1998) Change in body fat, but not body weight or metabolic correlates of obesity, is related to symptomatic relief of obese patients with knee osteoarthritis after a weight control program. J Rheumatol 25:2181-2186

31. Rasouli N, Kern PA (2008) Adipocytokines and the metabolic complications of obesity. J Clin Endocrinol Metab 93:S64-S73. doi:10.1210/jc.2008-1613

32. Vuolteenaho K, Koskinen A, Moilanen E (2014) Leptin - a link between obesity and osteoarthritis. Applications for prevention and treatment. Basic Clin Pharmacol Toxicol 114:103-108. doi:10.1111/bcpt.12160

33. Berry PA, Jones SW, Cicuttini FM, Wluka AE, Maciewicz RA (2011) Temporal relationship between serum adipokines, biomarkers of bone and cartilage turnover, and cartilage volume loss in a population with clinical knee osteoarthritis. Arthritis Rheum 63:700-707

34. Iwamoto J, Takeda T, Sato Y, Matsumoto H (2011) Serum leptin concentration positively correlates with body weight and total fat mass in postmenopausal Japanese women with osteoarthritis of the knee. Arthritis 2011:580632. doi:10.1155/2011/580632

35. Staikos C, Ververidis A, Drosos G, Manolopoulos VG, Verettas DA, Tavridou A (2013) The association of adipokine levels in plasma and synovial fluid with the severity of knee osteoarthritis. Rheumatology 52:1077-1083. doi:10.1093/rheumatology/kes422

36. Pallu S, Francin PJ, Guillaume C, Gegout-Pottie P, Netter P, Mainard D, Terlain B, Presle N (2010) Obesity affects the chondrocyte responsiveness to leptin in patients with osteoarthritis. Arthritis Res Ther 12:R112. doi:10.1186/ar3048

37. Griffin TM, Huebner JL, Kraus VB, Yan Z, Guilak F (2012) Induction of osteoarthritis and metabolic inflammation by a very high-fat diet in mice: effects of short-term exercise. Arthritis Rheum 64:443-453. doi:10.1002/art.33332

38. Simopoulou T, Malizos KN, Iliopoulos D, Stefanou N, Papatheodorou L, Ioannou M, Tsezou A (2007) Differential expression of leptin and leptin's receptor isoform $(\mathrm{Ob}-\mathrm{Rb})$ mRNA between advanced and minimally affected osteoarthritic cartilage; effect on cartilage metabolism. Osteoarthr Cartil $15: 872-883$

39. Dumond H, Presle N, Terlain B, Mainard D, Loeuille D, Netter P, Pottie P (2003) Evidence for a key role of leptin in osteoarthritis. Arthritis Rheum 48:3118-3129

40. Gandhi R, Takahashi M, Syed K, Davey JR, Mahomed NN (2010) Relationship between body habitus and joint leptin levels in a knee osteoarthritis population. J Orthop Res 28: 329-333. doi:10.1002/jor. 21000

41. Lübbeke A, Finckh A, Puskas GJ, Suva D, Lädermann A, Bas S, Fritschy D, Gabay C, Hoffmeyer P (2013) Do synovial leptin levels correlate with pain in end stage arthritis? Int Orthop 37:2071-2079

42. De Boer TN, van Spil WE, Huisman AM, Polak AA, Bijlsma JW, Lafeber FP, Mastbergen SC (2012) Serum adipokines in osteoarthritis; comparison with controls and relationship with local 
parameters of synovial inflammation and cartilage damage. Osteoarthr Cartil 20:846-853

43. Schäffler A, Ehling A, Neumann E, Herfarth H, Tarner I, Schölmerich J, Müller-Ladner U, Gay S (2003) Adipocytokines in synovial fluid. JAMA 290:1709-1710

44. Choe JY, Bae J, Jung HY, Park SH, Lee HJ, Kim SK (2012) Serum resistin level is associated with radiographic changes in hand osteoarthritis: cross-sectional study. Joint Bone Spine 79:160-165

45. Filková M, Lisková M, Hulejová $\mathrm{H}$, Haluzík M, Gatterová J, Pavelková A, Pavelka K, Gay S, Müller-Ladner U, Senolt L (2009) Increased serum adiponectin levels in female patients with erosive compared with non-erosive osteoarthritis. Ann Rheum Dis 68:295-296
46. Fadda SM, Gamal SM, Elsaid NY, Mohy AM (2013) Resistin in inflammatory and degenerative rheumatologic diseases. Relationship between resistin and rheumatoid arthritis disease progression. Z Rheumatol 72:594-600

47. Koskinen A, Juslin S, Nieminen R, Moilanen T, Vuolteenaho K, Moilanen E (2011) Adiponectin associates with markers of cartilage degradation in osteoarthritis and induces production of proinflammatory and catabolic factors through mitogen-activated protein kinase pathways. Arthritis Res Ther 13:R184

48. Honsawek S, Chayanupatkul M (2010) Correlation of plasma and synovial fluid adiponectin with knee osteoarthritis severity. Arch Med Res 41:593-598 